\title{
Teaching whole-number multiplication to promote children's proportional reasoning: a practice-based perspective from Japan
}

\author{
Keiko Hino ${ }^{1} \cdot$ Hisae Kato ${ }^{2}$ \\ Accepted: 24 August 2018 / Published online: 31 August 2018 \\ (c) The Author(s) 2018
}

\begin{abstract}
Whole-number arithmetic is a core content area of primary mathematics, which lays the foundation for children's later conceptual development. This paper focuses on teaching whole-number multiplication (WNM) to build a stepping stone for children's proportional reasoning. Our intention in writing this paper is to obtain a practice-based perspective on the teaching of WNM, given the growing attention being given to significant connections between children's understanding of multiplication and their proportional reasoning. To this end, we review studies on teaching WNM that were conducted in Japan. Our review highlights several aspects of teaching WNM that are integral to building an initial understanding of proportional relationships. Linear representations such as tape diagrams and number lines are also found to help make explicit the important properties of proportional relationships that can be used progressively across grade levels.
\end{abstract}

Keywords Multiplication $\cdot$ Proportional reasoning $\cdot$ Lesson study $\cdot$ Linear representation

\section{Introduction}

Many researchers have suggested that multiplication differs significantly from addition and subtraction (e.g., Clark and Kamii 1996; Fuson 2003; Vergnaud 1983, 1994; Verschaffel et al. 2007; Young-Loveridge and Bicknell 2015; Nunes et al. 2016). In addition and subtraction, quantities of the same type are added or subtracted (e.g., three apples and four apples). However, multiplication and division involve quantities of different types (e.g., two boxes with three apples per box). This inherent difference makes multiplication not just a faster way of doing repeated addition; it is an operation that requires children to think at a higher level compared to thinking additively (Clark and Kamii 1996). Nunes et al. (2016) stated, "Additive reasoning is based on quantities connected by part-whole relations; multiplicative reasoning is based on quantities connected by one-tomany correspondences or ratios" (p. 18). Therefore, it is apparent that we must grasp the fundamental structure of

Keiko Hino

khino@cc.utsunomiya-u.ac.jp

Utsunomiya University, Utsunomiya, Japan

2 Hyogo University of Teacher Education, Kato, Japan multiplication and division when teaching whole-number multiplication (WNM).

Herein, we construct our argument by locating WNM in a broader framework (Vergnaud 1983, 1994) in which proportionality is the core structure of interconnected topics. Our strategy for teaching WNM is to attend to the aspect of proportional relationships at an early stage by foreseeing smooth progression of children's proportional reasoning in later grades.

Furthermore, two observations stimulate our attention to teaching WNM in relation to proportional reasoning. First, there is a considerable research base concerning the development of proportional reasoning (e.g., Lesh et al. 1988; Harel and Confrey 1994; Lamon 2007; Nunes et al. 2016). However, this body of research is not always transparent when teaching different topics in a school mathematics curriculum (e.g., Shield and Dole 2013; Dole et al. 2015). In particular, a crucial problem is weak teacher recognition of the relationship between different mathematics topics and the development of proportional reasoning (Dole et al. 2015). Second, regarding WNM, several researchers have highlighted the important role of WNM teaching in fostering children's early proportional reasoning (e.g., Resnick and Singer 1993; Christou and Philippou 2002). Recently, research on early mathematics has also shown the importance of children's multiplicative reasoning, patterning, 


\begin{tabular}{|c|c|c|c|c|c|}
\hline \multicolumn{2}{|c|}{ Multiplication } & \multicolumn{2}{|c|}{ Division type 1} & \multicolumn{2}{|c|}{ Division type 2} \\
\hline M1 & M2 & M1 & M2 & M1 & M2 \\
\hline 1 & $\mathrm{a}$ & 1 & $\square$ & 1 & $\mathrm{a}$ \\
\hline $\mathrm{b}$ & $\square$ & $\mathrm{b}$ & $\mathrm{c}$ & $\square$ & $\mathrm{c}$ \\
\hline
\end{tabular}

Fig. 1 The first basis of MCF (Vergnaud 1994)

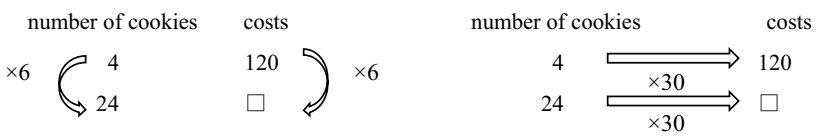

$$
\begin{aligned}
& \text { Scalar ratios } \\
& \text { Functional rates }
\end{aligned}
$$

Fig. 2 Scalar ratios and functional rates

and spatial structuring as foundations of their mathematical development (e.g., Mulligan 2011; Young-Loveridge and Bicknell 2015). Given the advancement of these theoretical underpinnings, we believe it is timely to obtain a practicebased perspective on the teaching of WNM in order to forge good connections between theory and practice.

For these reasons, the present paper investigates aspects of teaching WNM to build a stepping stone for children's understanding of proportional relationships and to promote their proportional reasoning, by reviewing relevant Japanese studies on lessons and teaching practices.

\section{Whole-number multiplication in the multiplicative conceptual field}

Multiplication and division with whole numbers form a web of interconnected topics because of their connections with fractions, measurement, ratios and rates, and proportional reasoning. This web of interconnected topics is known as the multiplicative conceptual field (MCF) (Vergnaud 1983, 1994). According to Vergnaud, the main categories of multiplicative structures are simple proportion, concatenation of simple proportions, double proportion, and comparison of rates and ratio (Vergnaud 1994, p. 48). These situational categories involve linear and bilinear functions, linear mapping, and linear combinations of magnitudes. Although the mathematical structure remains the same, each category covers situations that involve different levels of cognitive complexity.

Simple proportion provides children with their first meaning for multiplication and division and forms the basis for the first MCF. Situations in the category of simple proportions are distinguished among three sub-categories (Fig. 1). Two different operations are also distinguished, namely scalar ratio and functional rate (see Fig. 2 for the example of finding the costs of 24 cookies). By the end of primary school, children are expected to use those operations to deal with different situations that involve proportional relationships.

MCF theory justifies teaching WNM by attending to its proportional relationships. The hallmark of interconnections in the MCF is proportionality: children must make progress toward dealing with more-complex situations involving proportional relationships with different types of quantities, magnitudes, operations, and signifiers. When teaching WNM, teachers should recognize the progressions that children are expected to make and help them construct schemes that work in various multiplicative situations.

MCF theory also justifies studying linguistic and extralinguistic means in WNM teaching. The concepts and theorems-in-action are conceptual in the sense that they are not always symbolized externally (Vergnaud 1994). Words and symbols are crucial in helping children to identify invariants and so make them visible. They are also important in making implicit concepts and theorems explicable, debatable, and public, all three of which are necessary for constructing mathematical concepts and theorems. Therefore, when teaching WNM, how to introduce and use linguistic and extralinguistic means by foreseeing later development is important.

\section{Essentials for developing proportional reasoning}

In the MCF, WNM is about the structure of simple proportion. Therefore, proportional reasoning is the object of our attention. From accumulated research on proportional reasoning, researchers have developed theoretical constructs and language that play key roles in understanding and discussing the development of children's proportional reasoning (e.g., Kaput and West 1994; Lamon 2005, 2007; Lobato et al. 2010; Nunes et al. 2016). Drawing mainly on the work by Lamon (2005), we describe several aspects of proportional reasoning that we think are significant to the teaching of WNM.

\subsection{Relative thinking}

There are two perspectives on analyzing change. If plant $\mathrm{A}$ grows from 2 to $6 \mathrm{~m}$ and plant $\mathrm{B}$ grows from 4 to $8 \mathrm{~m}$, which grew more? One answer is that both plants grew the same because both changed by $4 \mathrm{~m}$. This perspective is called absolute thinking and involves looking at the actual (or absolute) change in terms of how much quantity is added. The growth is considered unrelated to anything else. Another perspective is to look at the change relatively by relating the growth of each plant to its initial length. Therefore, plant A grew to three times its initial length whereas plant B grew 
to twice its initial length; therefore, plant A grew more. This perspective is called relative thinking (Lamon 2005).

A critical component of proportional reasoning is "to analyze change in both absolute and relative terms" (Lamon 2005, p. 30). In fact, children's lack of ability in this type of analysis has been reported extensively (e.g., Modestou and Gagatsis 2010; Van Dooren et al. 2010). Children prefer absolute thinking even when relative thinking is required; they also calculate multiplication and division mechanically when absolute thinking is required. In particular, it is crucial to go beyond absolute thinking to acquire powerful ways of thinking.

Relative thinking involves forming a ratio by comparing two quantities multiplicatively (multiplicative comparison) (Lobato et al. 2010). According to Lobato et al., relative thinking asks, "How many times greater is one thing than another?" or "What part or fraction is one thing of another?" (p. 18). It constitutes an essential understanding of ratios, proportions, and proportional reasoning.

\subsection{Measurement}

Numbers arise from measuring one quantity in terms of another quantity that is taken to be the unit, and assigning a numerical value by knowing how much (or many) of that unit is (are) needed to constitute the given quantity (Bass 2015). Measurement is a starting point for mathematics and also plays an important role in understanding rational numbers and in multiplicative thinking (Lamon 2005).

Lamon (2005) also states the importance of understanding measurement principles (p. 42). The compensatory principle involves the relationship between the size of the unit of measure and the numerical value assigned to the quantity being measured. If the unit is smaller, more are needed to measure the quantity, and vice versa. The approximation principle is that a measurement is always approximate and can be made more accurate to whatever degree. The recursive partitioning principle is as follows: when measuring an amount that is smaller than the unit, a new subunit can be adopted by breaking the original unit into some equal number of subunits and by using one of the subunits as a new unit of measure. This process can be repeated recursively.

\subsection{Reasoning up and down}

Proportional reasoning involves a simple form of covariation. Children require the ability to reason up and down (Lamon 2005), which is the process of establishing a ratio and then extending it to another ratio to find the missing value or to make a comparison. What is essential is that the transformation preserves the same ratio relationship between the two quantities.
Children are observed to go through this process in different ways. An early strategy that children use is the building-up strategy, which involves finding the value by incrementing the initial amount by addition. An example of such reasoning is as follows: "Four cookies cost 120 yen, so eight cookies cost 240 yen because having four more cookies requires another 120 yen. Twelve cookies cost 360 yen because having four more cookies requires another 120 yen $(240+120=360)$, and so on." Because not all children will recognize the multiplicative ratio relationship, the buildingup strategy should not be labeled simply as proportional reasoning (Lamon 2005, 2007).

When children start using multiplication and division in their process of building up and down, it becomes more efficient and can be called proportional reasoning. Such reasoning is described as an abbreviated build-up/build-down processes using multiplication and division by Kaput and West (1994, p. 244). Further elaboration of the buildingup strategy is the unit factor approach, in which two given quantities are used as divisor and dividend to form the unit factor (i.e., a rate) (Kaput and West 1994, p. 250).

\subsection{Unitizing and norming}

In reasoning up and down, the process of unitizing is deemed critical (Lamon 2005, 2007). Unitizing is "the cognitive chunking or regrouping of a given quantity into manageable or conveniently sized parcels" (Lamon 2007, p. 644) and involves the cognitive process of subitizing. Twentyfour cakes can be unitized differently by choosing different composite units, such as 12 pairs, two dozens, or four boxes of six cakes. It is essential that in these different composite units, the quantity itself does not change. In the problemsolving process, the formed composite unit is used to reinterpret the given situation in terms of that unit. Such "reconceptualization of a system in relation to some fixed unit or standard" is called norming (Lamon 1994, p. 94).

Proportional reasoning requires constructing a "higherorder group containing the A unit and the B unit as its two elements" (Kaput and West 1994, p. 247). Lobato et al. (2010) called it "a composed unit" (p. 19), which is a new unit formed by composing (joining) two quantities in a way that preserves a multiplicative relationship. "For seven silver, there is four china" (Kaput and West 1994, p. 246) and "10 cm in 4 s" (Lobato et al. 2010, p. 19) offer examples of composed unit. The ability to choose a composed unit flexibly depending on the situation or context and exercise reasoning up and down is considered to be a salient feature of proportional reasoners (e.g., Lamon 2005, 2007; Kaput and West 1994; Lo and Watanabe 1997). Furthermore, Lobato et al. (2010) noted that understanding the relationship between a composed unit and multiplicative comparison is essential for proportional reasoning. 


\section{Rationale and research question}

\subsection{Tasks for teaching WNM in the research on early proportional reasoning}

Most research on proportional reasoning is conducted with children in the middle years of schooling because ratio and proportion are typically taught then. However, some studies discuss proportional reasoning in young children. Below, we describe tasks and suggestions for WNM teaching from the studies by Resnick and Singer (1993) and Christou and Philippou (2002).

Resnick and Singer (1993) discuss the intuitive origins of proportion and ratio reasoning. They contend that young children have a set of proto-quantitative relational schemes that enables them to reason about ratio- and proportion-like relationships without numerical quantification. However, when children begin trying to quantify their reasoning about situations involving proportions, they use proto-ratio reasoning, which involves coordinating two numerical series additively without forming a single ratio quantity. The building-up strategy is one type of protoratio reasoning. Resnick and Singer (1993) point out that one reason for children's early preference for proto-ratio reasoning and additive strategies is their weakly developed knowledge of the factorial (multiplicative) structure of numbers. They go on to say that "school practice very likely plays a more definitive role in the development of ratio reasoning than in earlier mathematical development" (p. 126). Nevertheless, "how best to help children develop fluent and flexible command of the factorial structure of numbers has not been fully addressed in the research literature" (p. 127). They suggest an indirect teaching approach, including discussing multiple solutions or systematic forms of record keeping, for future work.

From interviews with fourth and fifth graders, Christou and Philippou (2002) discuss the intuitive models that young children form for proportion problems. They found that the most prevalent solution strategy was the unit-rate strategy, which is "a two-step process in which the cost or value of 1-item is computed and then multiplied by the desired number of items" (p. 327). Furthermore, the method was so prevalent that children did not feel the need to seek other methods, even when they did not reach a reasonable solution. According to Christou and Philippou (2002), children's use of the unit-rate method indicates an attempt to draw on knowledge they have developed from the experience of solving simple multiplicative problems. Based on these findings, they state, "Instruction should thus provide opportunities for students to learn that in some contexts, the unit method might be the preferable method, but, under slightly different circumstances, other options may be preferable" (Christou and Philippou 2002, p. 335). They say that instruction needs to be sought regarding how to build upon children's informal knowledge to develop their awareness of the appropriateness of strategies and to motivate the decision-making process.

These previous studies commonly indicate the significant influence of WNM teaching on children's development of proportional reasoning. Moreover, they commonly argue for the need of better WNM teaching. Their suggestions for better approaches are very informative. Nevertheless, they remain more as theoretical suggestions than as empirically verified conclusions. In this regard, obtaining information from practice-based studies on WNM lessons is worth pursuing.

\subsection{Research question}

Based on the rationale described above, we review the literature on teaching WNM in Japan. Therefore, this paper addresses the following research question.

- What can previous studies in Japan tell us about classroom activities, including the use of visual representations that can be linked to children's early understanding of proportional reasoning?

\section{The study}

There are two reasons for choosing Japan as the site for the literature review. First, the Japanese curriculum emphasizes quantitative relationships, including proportional relationships (Hino 2015). A major feature in this regard is the existence of the Quantitative Relation strand in the four curricular strands (e.g., Ministry of Education, Culture, Sports, Science and Technology [MEXT] 2008). This strand contains learning of the methods and tools of thinking mathematically and is often taught by being integrated into the content of other strands. The idea of function is one of three methods included in this strand. The emphasis is on the two co-varying quantities rather than on patterns such as repeating or growing ones (Watanabe 2011). Accordingly, the idea of function arises in WNM teaching by stressing relationships among the multiplicand, multiplier, and product. Curricular materials are created to learn these relationships and to prepare for smooth progression toward the learning of ratio and proportion.

Second, Japan is well-known for having the tradition of lesson study (e.g., Stigler and Hiebert 1999). Regarding WNM teaching, there exist a certain number of lesson studies with different themes and results. These practice-based studies are expected to contain useful information about effective ways of teaching WNM in the classroom. 


\subsection{Approach to teaching the meaning of WNM in Japan}

How to teach multiplication is the result of much discussion and research among mathematics educators in Japan. In the teaching guide for the Course of Study (MEXT 2008), the meaning of multiplication of whole numbers, decimals, and fractions is represented as $\mathrm{B} \times \mathrm{P}=\mathrm{A}$, where $\mathrm{B}$ is the base quantity, $\mathrm{P}$ is the relative value, and $\mathrm{A}$ is the corresponding quantity that has the specified relative size with respect to $\mathrm{B}$. The fact that the product becomes smaller than the multiplicand $\mathrm{B}$ when the multiplier $\mathrm{P}$ is smaller than one can be explained using a number-line (Fig. 3).

Aiming at children's acquisition of the meaning of multiplication $\mathrm{B} \times \mathrm{P}=\mathrm{A}$, teaching of the meaning of WNM has also been discussed with respect to three approaches (Society of Elementary Mathematics Education 2011):

(i) a shorter way of writing repeated addition;

(ii) (how many objects in a unit) $\times$ (how many units);

(iii) (amount per unit) $\times$ (how many whole number or fractional units).

In meaning (i), $4 \times 3$ is introduced as the way of reexpressing $4+4+4$ concisely. However, this meaning of repeated addition fails to work when the multiplier is a decimal or a fraction. Meaning (ii) involves finding the
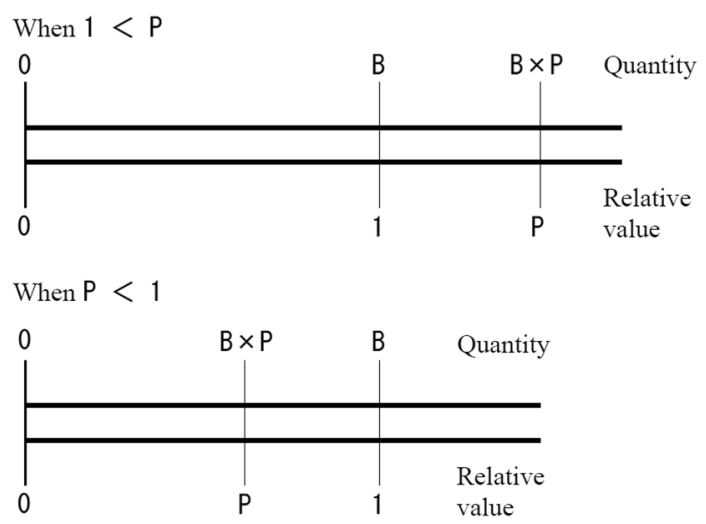

Fig. 3 Meaning of multiplication (English translation of MEXT 2008, p. 154) total number of objects when there are several groups of objects that have the same number in each group. In this approach, the purpose of $4 \times 3$ is to find the total number of people when there are three cars and each car contains four people. Repeated addition arises when calculating the answer. Therefore, the meaning of multiplication is independent of addition but not disconnected completely. Meaning (iii) relies on rate; the purpose of $4 \times 3$ is to find the total number of legs when there are three dogs (with four legs per dog). The word per is stressed by devising suitable situations for the meaning of "per unit quantity." This meaning of multiplication is independent of repeated addition. The answer must be obtained by a method other than repeated addition, such as skip counting or using rectangular arrays.

The current curriculum in Japan adopts meaning (ii). Meaning (iii) is the approach of introducing a generally workable meaning of multiplication from the beginning. However, the problem is that the concept of rate is considerably more difficult for early-grade children in understanding both the concept itself and its necessity. It is also difficult to teach how to get the answer because of the disconnection of meaning (iii) from repeated addition. Although not sufficiently general, meaning (ii) is conceived as being more natural for children and serving their construction of the meaning of multiplication. Furthermore, because meaning (ii) is the "groups of" conception of multiplication (e.g., $4 \times 3$ as "three groups of four"), it involves a one-to-many correspondence that is fundamental to multiplicative thinking and proportional reasoning (Lobato et al. 2010). In this approach, it is necessary to extend the meaning of multiplication when the multiplier becomes zero, a decimal, or a fraction. Nevertheless, different from meaning (i), the forthcoming discrepancies are thought to be narrowed by this conception of multiplication.

Visual representations that support meaning (ii) are also important (Society of Elementary Mathematics Education 2011). The representations shown in Fig. 4 are encouraged because they have the advantage of being able to be used beyond WNM. Figure $4 \mathrm{~b}$ shows a double-number-line that can be presented when children are taught multiplication tables. It shows the case of multiples of two, and the lower line indicates the result of multiplication $\mathrm{A} \times \mathrm{B}$.
Fig. 4 Multiplication in (a) a table and (b) a double number line (Society of Elementary Mathematics Education 2011, p. 112 , revised) (a)

\begin{tabular}{|lllll|}
\hline 0 & 1 & 2 & 3 & $\cdots \cdots$ \\
\hline 0 & 2 & 4 & 6 & $\cdots \cdots$ \\
\hline
\end{tabular}

(b)

\begin{tabular}{|lllll|l|}
\hline 0 & 1 & 2 & $3=\mathrm{B}$ & 4 \\
\hline & & & & & \\
\hline
\end{tabular}




\subsection{Method of study}

Our review draws on data from the Journal of Japan Society of Mathematical Education (JSME), the Proceedings of the Annual Meeting of the JSME, and a periodical entitled Elementary Mathematics Teaching Today. The aforementioned journal and proceedings are edited by the JSME, which is one of the representative associations for mathematics education in Japan. The third publication is a wellread periodical edited by a publishing company. Its main readers are teachers in primary schools, and it includes articles on teaching practices and lesson studies. In the present review, we chose articles that were published between 1998 and 2017, covering the 1998 and 2008 revisions of the Course of Study for primary schools. They emphasize mathematical activities that are still ongoing today and are stable in the teaching of WNM.

The review process comprised two steps. First, we searched the electronic CiNii Articles database with the keywords "whole-number," "multiplication," and "primary school." We also searched print indices from Elementary Mathematics Teaching Today. We obtained 69 articles in total, which we classified into four categories by the key words given in each article; we assigned key words to those articles that had none. The resultant categories were "theoretical analysis of the meaning of multiplication" (13 articles), "implication for teaching from historical analysis" (two articles), "perspective of early algebra" (two articles), and "practice-based study on multiplication" (52 articles). Second, we focused on the category of practicebased study and further classified those 52 articles into five categories according to the themes of those studies. Of the five categories, three were ones concerning WNM in relation to proportional reasoning, which we describe in the next section. The other two categories were "teaching of multiplication tables" (10 articles) and "others" (14 articles), the latter including topics such as algorithms of multiplication and finding area. In the present review process, one of the present authors developed a set of categories and the other author checked them by reading some of the articles. We shared the results and discussed and modified the classifications when discrepancies emerged.

\section{Results}

In this section, we describe the three categories of studies that are connected to our research question. Because of limited space, for each category we first give our overall observations and then show an example of WNM teaching.

\subsection{Forming the basis for relative thinking}

This category includes 10 studies that were aimed at fostering children's relative thinking at an early stage when comparing and measuring quantities. These studies value children's early recognition of $\mathrm{B} \times \mathrm{P}=\mathrm{A}$. We classified them into three sub-categories. In the first grade, children learn three ways of comparing quantities, namely direct and indirect comparison and comparing quantities using arbitrary units (MEXT 2008). When teaching the third way, studies in the first sub-category stress children's recognition of B by providing multiple arbitrary units (e.g., small cup and large cup) and encouraging them to think about the need for a common unit in order to make comparison (e.g., Kako 2015). In the second grade, children are introduced to the term bai (倍) (meaning " $x$ times as many (much) as"). Bai refers to the relative value $\mathrm{P}$ or the relational concept (Kugaya 2017), even though at this stage it is usually not stressed very much. Studies in the second sub-category consider bai as indispensable and stress children's meaningful encounters with this concept (e.g., Ichikawa 2010; Takashima 1999). In the third-grade, children are taught that bai can be found by using division. In the later grades, bai is used as the pivoting concept for extending the meaning of multiplication to decimals and fractions (MEXT 2008). Studies in the third subcategory were aimed at deepening children's understanding of bai when they encounter situations in which the use of bai is extended from whole numbers to decimals in the fourth grade (e.g., Kugaya 2017; Tabata 2001).

\subsubsection{Study 1}

Ichikawa (2010) conducted a lesson in the second grade that was focused on introducing bai. His aim in developing the lesson was to improve instruction so that children pay more attention to the meaning of bai. In the lesson, the teacher showed two types of recorder (i.e., the musical instrument) and motivated the children to find out how long they were. The children proposed using their fists. After ensuring their way, each child measured the length of a recorder and obtained results such as five fists or six fists. Next, the teacher reproduced the process of measuring the length of a recorder by presenting a picture (Fig. 5) on the blackboard, introduced the word bai, and wrote, "The length of a recorder is five bai of a fist." The teacher changed "five" in the sentence to "four," "three," and "two" and asked the children, "What can we say if the recorder is valued as just one fist?" They clarified "one bai" at this point.

The lesson proceeded to change the picture to a tape (i.e., a long narrow strip). Here the teacher turned over the picture of five fists and presented it as a tape (Fig. 6). Finally, the teacher asked the children what happens if they change the unit. They changed the fist from their own to that of adult. 


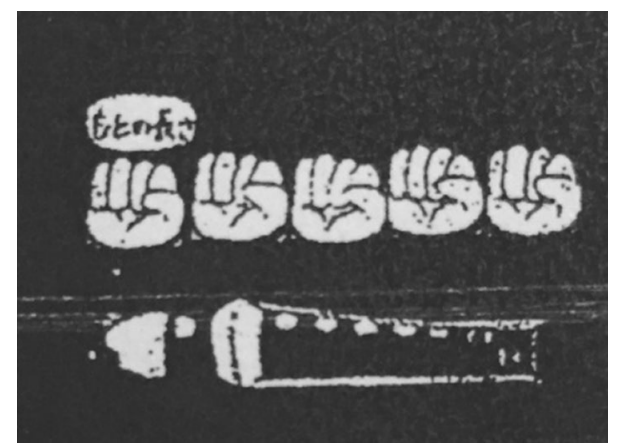

Fig. 5 Length of a recorder measured in fists (Ichikawa 2010, p. 135)

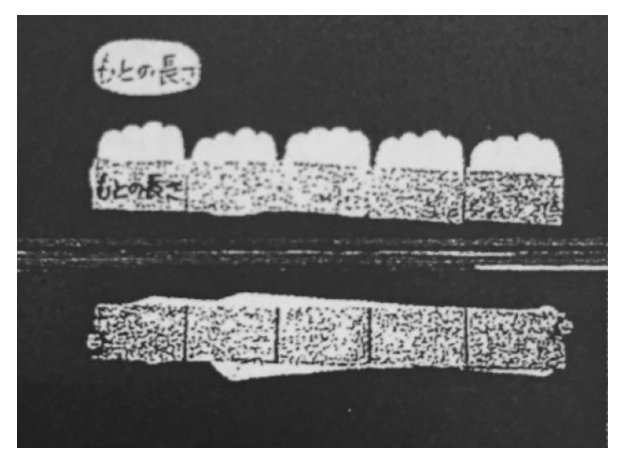

Fig. 6 Representation of five fists as a tape (Ichikawa 2010, p. 136)

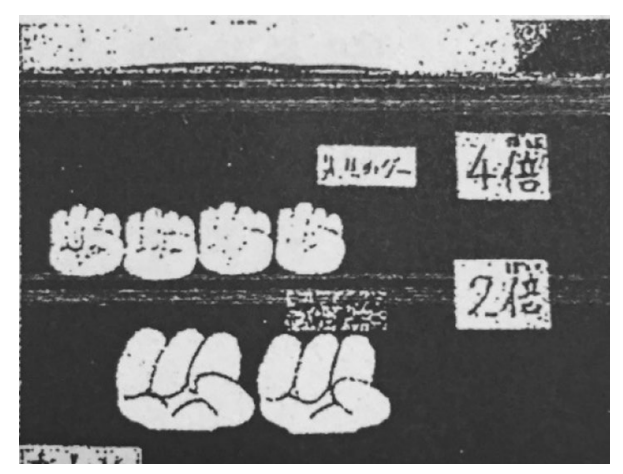

Fig. 7 Teacher's fists and Mickey's fists (Ichikawa 2010, p. 136)

The teacher measured the length of a recorder using his fist, resulting in four bai. The children wanted to use bigger fists, such as those of another teacher or a lion or elephant. The teacher presented the fist of Mickey Mouse. They realized that the recorder is valued as two bai of Mickey's fist (Fig. 7). The lesson ended by summarizing the new word "bai," the meaning of one bai, and the observation that the bai changes if the unit is changed.

By collecting the data of the video-recorded lesson, the children's written reflections of the lesson, and postinstruction assessment, Ichikawa showed that the lesson had

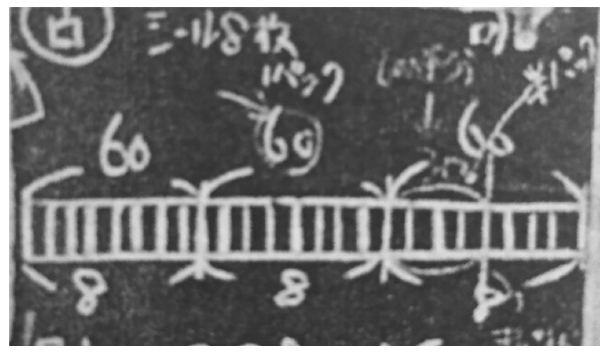

Fig. 8 A child's thinking with a tape diagram (Takahashi 2015, p. 6)

a certain effect on the children's early recognition of the relationship among base quantity, given quantity, and bai. For example, when discussing measuring the length in the lesson, the children verbalized phrases involving bai or base quantity, such as "this recorder is four bai of the teacher's fist" or "it [the result] will change according to the base length." In their written reflections, the children also wrote about their surprise in finding that the length changed value according to the base length.

\subsection{Coordinating two quantities by generating a composed unit}

This category includes 12 studies that enhance children's ability to attend to and coordinate two quantities when solving multiplicative word problems in the third and/or fourth grade(s). We developed two sub-categories for these studies. One comprises those studies that focus more on the process of unitizing/norming with the composed unit (e.g., Nakamura 2011; Nunokawa 2007; Takahashi 2015). In the lessons of those studies, by controlling numerical/quantitative information in the task, the teachers encouraged the children to engage in unitizing and norming, and the class compared and discussed multiple solutions. The other sub-category comprises those studies that address the use of linear representations in which the children operate numbers (e.g., Aoyama 2013). In the study by Aoyama (2013), children in a class were studied over two years, in which they consistently used number-line diagrams. The children showed progress in using double number lines as they came to generate multiple composed units for use in coordinating two quantities.

\subsubsection{Study 2}

The purpose of the study by Takahashi (2015) was to foster third-grade children's ability to unitize quantities in a situation that involved determining the price of 20 stickers when one packet of eight stickers costs 60 yen. In the lesson, the answer was shared first and the children were invited to discuss their ways of reaching it. A child presented his or her thinking by using a tape diagram (Fig. 8), which 


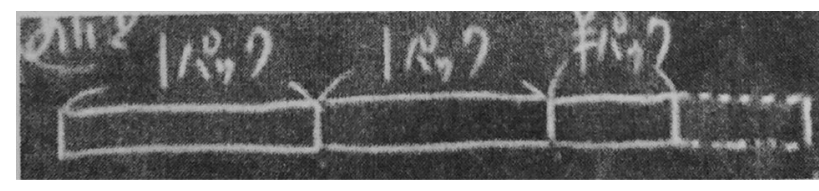

Fig. 9 Tape diagram with one packet and half a packet (Takahashi 2015, p. 7)

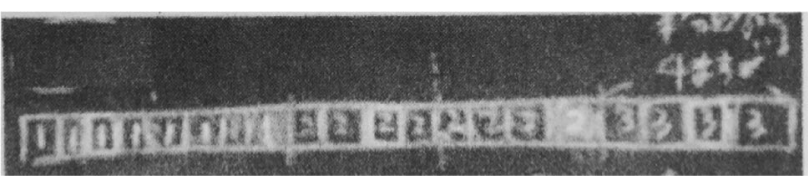

Fig. 10 A child's thinking with another tape diagram (Takahashi 2015, p. 9)

was a building-up strategy, for example $60+60+30=150$. In the interaction among the children about this solution, they began to utter "one packet" and "half a packet." Here, the teacher drew a tape (Fig. 9) to stress the composite unit in one quantity. Another child explained his thinking as, "I thought of [using] half a packet from the beginning." He developed the composed unit "30 yen for four" first and got the answer by norming the situation $30 \times 5$. The next child again showed a building-up strategy, namely $60 \times 2+60 \div 2$, by using a different tape diagram (Fig. 10). Yet another child generated a different composite unit, namely "half of half a packet," and a composed unit, namely " 15 yen for two stickers," and used the composed unit to find the price of 20 stickers by norming the situation $15 \times 10$.

Takahashi incorporated several means to foster children's unitizing abilities. First, the task did not contain a unit value (the price of one sticker). By removing that information, the teacher provided an opportunity for the children to think about what they should regard as one unit. Nakamura (2011) distinguished three levels of composed unit given in the task: (i) the unit value is given $(1 \mathrm{~m}$ costs 20 yen. How much do $3 \mathrm{~m}$ cost?), (ii) the unit value is not given, but the composed unit to be used is given ( $3 \mathrm{~m}$ cost 20 yen. How much do $9 \mathrm{~m}$ cost?), and (iii) the composed unit to be used is not given ( $4 \mathrm{~m}$ cost 20 yen. How much do $6 \mathrm{~m}$ cost?). Takahashi focused on children's unitizing abilities in the task of level (iii). In (iii), children are required to generate a suitable composed unit by themselves. As an initial activity for (iii), Takahashi controlled the numbers so that the children could generate the composed unit easily.

Second, the word packet was included in the task to enhance the children's attention to the composed unit. The setting "one packet contains eight stickers" makes it impossible for the third-graders to find the price of one sticker by division $(60 \div 8)$. The word packet was expected to help the children to contrive "four stickers" from "eight stickers" by reminding them of phrases such as half a packet.

Third, the teacher encouraged (or sometimes explicitly asked) the children to draw pictures and diagrams. The emphasis on communicating with visual representations was deemed vital to make clear the quantitative relationships in the task.

Takahashi analyzed the children's ability to unitize quantities from the data of recordings of the lesson, children's notebooks, and written reflections. To unitize four stickers as half a packet was within the children's ability. They developed two ways of making and using half a packet. They adjusted a composed unit either early or late in their reasoning process (Kaput and West 1994). Nevertheless, the children were thinking in between additively or multiplicatively, as shown by their regression to the buildingup strategy. They grasped the structure of the task either additively or multiplicatively. Such differences surfaced in the tape diagrams and mathematical expressions drawn by the children and provided those children with an opportunity for comparison. Takahashi concluded the importance of repeatedly providing mathematical activities that involve generating and deciding suitable composed units to solve different tasks involving level (iii).

\subsection{Promoting awareness of proportional relationships}

The third category includes six studies that address the issue of how to use the concept of proportional relationship as a unified structure when teaching multiplication and division. We developed two sub-categories. One comprises those studies that enhance children's recognition of the proportional relationship in the multiplication and division tasks, including WNM (e.g., Tabata 2008; Sato 2009). The other sub-category comprises those studies on teaching numberline representations to promote children's use of proportional reasoning when solving problems of multiplication and division (Iwasawa and Hino 2011; Tanaka 2016). Those studies either proposed using number-line representations in primary school or discussed when to teach the writing of double number lines.

\subsubsection{Study 3}

Tabata (2008) pointed out that there are different types of word problems involving proportional relationships: (i) an explicit expression is given that shows the assumption of a proportional relationship (e.g., we distribute apples with three apples for each person); (ii) the answer cannot be specified unless a proportional relationship is assumed (e.g., we buy $4 \mathrm{~m}$ of ribbon at the price of 30 yen for $1 \mathrm{~m}$ ); and (iii) the proportional relationship is contained inherently as 
a physical property (e.g., the weight of $4 \mathrm{~m}$ of wire with $3 \mathrm{~g}$ for $1 \mathrm{~m}$ ). The lesson on unit price that Tabata designed for the fourth grade was of type (ii).

There are many everyday situations in which the unit price decreases if one buys more. The purposes of the lesson were to make the children aware that the unit price situation dealt with in the lesson assumes a proportional relationship, and to foster the children's proportional reasoning by comparing the situation with those in daily life.

Two tasks dealt with in the lesson, and one post-lesson assessment task, were developed. In the lesson, the children were first asked to solve a task, namely "Three pingpong balls cost 690 yen. How much do 12 ping-pong balls cost?" Two solutions were presented by the children, namely $(690 \div 3) \times 12$ and $690 \times(12 \div 3)$. The teacher then drew two lines and wrote numbers on them, with arrows to show the proportional relationship (Fig. 11). The children themselves drew the double-number-line for the other solution and shared their results in a whole-class activity. The teacher then presented the next task of finding the price of 60 ping-pong balls. Here, the children solved the task and also drew its double-number-line representation (Fig. 12) and explained their solutions to their peers. At the end of the lesson, the teacher told the children that, in everyday life, the unit price may decrease when we buy many of the same goods at a time, and the children wrote their reflections.

In the post-lesson assessment, the children were asked to solve the following task: "In a sale, we want to sell 60 ping-pong balls at the price of 315 yen for three balls. What price do you assign? Please write the price and your reasons for it." Thirty-three out of 37 children wrote prices that involved subtracting some number from the solution they got by using a proportional relationship, such as, "Three balls cost 315 yen, so one ball costs 105 yen. But I will subtract 5 yen as a consumption tax." Their reasons showed that the children were aware that the unit price in everyday life does not always assume proportional reasoning, but that

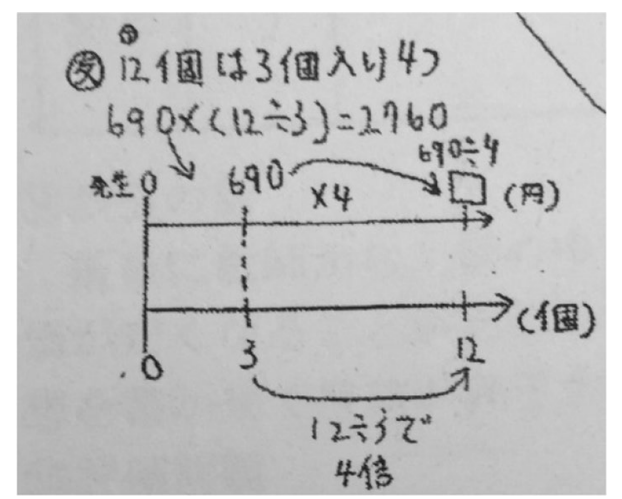

Fig. 11 Teacher's writing on the blackboard (from a student's notebook) (Tabata 2008, p. 342)

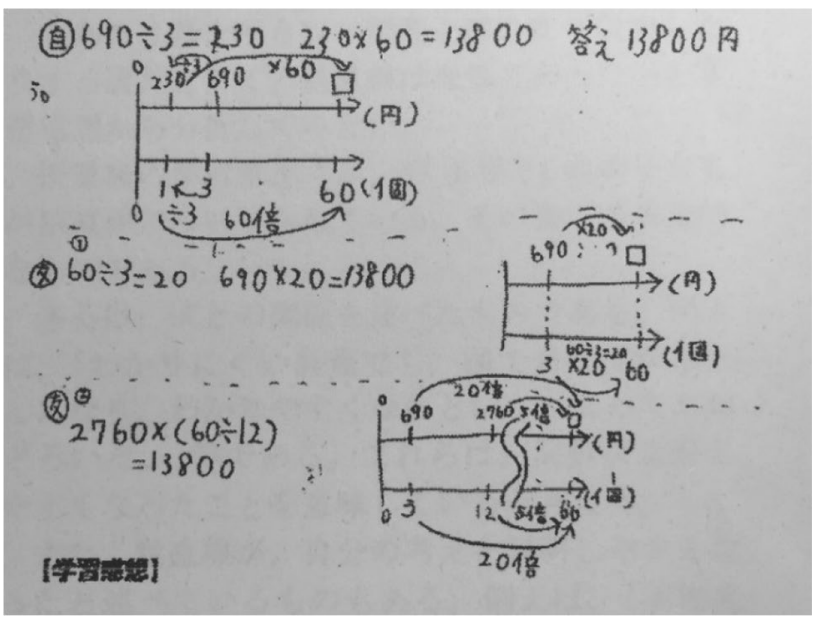

Fig. 12 Three children's thinking with double number lines (Tabata 2008, p. 342)

it is important to have certain criteria (price obtained by using a proportional relationship) when making a decision in everyday life.

\section{Discussion}

In the previous section, we described the results of our literature review in terms of three categories of studies. In the present section, we discuss what information we obtained about teaching WNM from the aspects of proportional reasoning and visual representation.

\subsection{Teaching multiplication as a proportional relationship}

Studies in the category of forming the basis for relative thinking suggest that it is important to teach the meaning of base quantity (B), relative value (P), and the corresponding quantity $(\mathrm{A})(\mathrm{B} \times \mathrm{P}=\mathrm{A})$ within a quantity (a measure space) in the early grades. Understanding the multiplier as a relative value is a critical basis for relative thinking that compares the relationship between two quantities (two measure spaces) by relative values $\mathrm{P}_{1}$ and $\mathrm{P}_{2}$. The reviewed studies (i) made use of situations that involved comparing and measuring quantities and (ii) carefully dealt with the process and necessity of quantification from a materialized proto-quantity. Furthermore, they commonly provided children with opportunities to experience the measurement principles, in particular the compensatory principle and the approximation principle (Lamon 2005). Such experiences were conceived as enhancing children's recognition of the relationship among $\mathrm{A}, \mathrm{B}$, and $\mathrm{P}$. 
To develop relative thinking, interpreting the multiplier as a relative value needs to be used further for comparing relationships between two quantities in proportional situations, although we could not find such studies in our review. For example, children can be asked, "Which rubbers stretch more, rubber $\mathrm{R}(10 \mathrm{~cm} \rightarrow 30 \mathrm{~cm})$ or rubber $\mathrm{S}(20 \mathrm{~cm} \rightarrow$ $40 \mathrm{~cm})$ ?" In this problem, the degree of stretch in each rubber is compared by using relative values (" 3 " for $\mathrm{R}$ and " 2 " for $\mathrm{S}$ ). The degree of stretch is a measure of attribute and assumes a proportional relationship between two quantities for the attribute of interest. To quantify the degree of stretch, children must consider other cases (not just the one given) involving the same rubber. Therefore, this activity connects to proportional reasoning and provides a basis for understanding ratio as multiplicative comparison (Lobato et al. 2010).

Studies in the category of coordinating two quantities by generating a composed unit are concerned with fostering the abilities of reasoning up and down and of unitizing and norming. In particular, they suggest WNM teaching that enhances moving from proto-ratio reasoning to ratio reasoning. First, the reviewed studies commonly used tasks that did not contain information about the unit value. They further devised situations that stimulated and guided the children to coordinate two quantities and generate and use a composed unit. Third- and fourth-graders could generate a composed unit and use it to find a missing value when the context was familiar and the number relationship was relatively easy. Including words in the problem statement that prompted batch imagery also helped the children to generate a suitable unit (see also Kaput and West 1994). Second, proto-ratio reasoning and additive thinking appeared repeatedly in the lessons of the reviewed studies. The teachers elicited those ways of thinking and provided children with opportunities to either compare multiple solutions or make them the object of discussion.

These attempts stimulate the idea of developing WNM lessons to enhance children's awareness of appropriate strategies and the decision-making process. The teachers elicited multiple ways of thinking and encouraged comparisons, as suggested by Resnick and Singer (1993) and Christou and Phillippou (2002). Nevertheless, an issue addressed in our review is how to fine-tune a lesson to the current cognitive level of the children for whom it is intended. For example, variation exists even in the building-up strategy. What children can do regarding unitizing and norming also varies substantially. Nakamura (2011) highlighted the gap between unitizing and norming, especially the difficulty of norming, which was seen in the children's regression to addition of the units generated in study 2. Further study is required on the process of comparing multiple solutions by adjusting it to children's learning trajectories regarding unitizing and norming.
In the category of promoting awareness of proportional relationships, the teachers aimed at moving implicit proportional relationships to those addressed more explicitly, so that children can pay attention to the invariance of proportional relationships across multiplicative situations. WNM is conceived as the first opportunity for such long-term development. The teachers in the studies of this category did not use the unit value in the task either. Children were also prompted to explain their thought processes in their own words or with tape diagrams or number lines.

The attempts in this category seem to show another way to enhance children's decision-making in proportional situations by building their reasons. There is a reason why proportional reasoning is applicable in some situations but not in others. The studies attended to the assumption of proportional relationship underlying problem situations. Consistent representations were critical in these studies and were often double number lines. Attending to the assumption of proportional relationships is important to develop certain criteria that will work when making decisions.

\subsection{Using linear representations to make explicit the invariants of a proportional relationship}

Vergnaud (1994) stressed the importance of explication and formulation of implicit invariants to recognize the same structure and generalize it to other situations. Almost all studies in our review adopted linear representations such as tape diagrams and double number lines as the means of explication.

The observed tape diagrams might be thought of as similar to ratio tables in how they make explicit the invariance of a proportional relationship. Tabular representation depicts and organizes information in ratio, rate, or proportion situations in such a way as to support the analysis of multiplicative relationships in terms of within and between measure spaces (Vergnaud 1983, 1994). In addition, tape diagrams support the representation of quantity more visually because the magnitude is shown by the length of a tape (a thin rectangle). It is also easy to see that each length within a single tape represents the same quantity (see also Orrill and Brown 2012). In this way, tape diagrams have an idiosyncratic feature to provide a visual way of making sense of and coordinating two given quantities.

We can see the use of strip (or bar) diagrams in the curriculum of Singaporean primary schools (e.g., $\mathrm{Ng}$ and Lee 2009; Kaur 2015). Their use of strips to model information presented in word problems is called the model method. It involves drawing strip diagrams to represent key information in the task, especially by using knowledge about the part-part-whole relationship of numbers ( $\mathrm{Ng}$ and Lee 2009, p. 292). Its purpose is to offer children early access to solving word problems algebraically by circumventing the need 
to construct and solve linear algebraic equations ( $\mathrm{Ng}$ and Lee 2009). Compared with this approach, the use of tape diagrams in our reviewed studies is intended to promote children's early recognition of multiplication as a proportional relationship. It is expected that children will come to use them spontaneously as problem-solving strategies and as explanatory tools in multiplicative situations.

Furthermore, the number-line representation lays the foundation for numbers (Sugiyama 2008) and provides a coherent connection across grade levels (Bass 2015). The results of the present review indicate a developmental progression of linear representations from (i) a picture of aligned concrete objects to (ii) a tape (thin rectangle) with scaling to (iii) a parallel drawing of a tape and a number-line and finally to (iv) a double-number-line. It is worth noting that using a double-number-line is the final stage of that development, given the reported difficulty in using doublenumber-line representations (e.g., Orrill and Brown 2012).

Nevertheless, we must consider the effectiveness of our approach of linear representations for preparing children to become powerful proportional reasoners. The double-number-line is considered to be a promising tool for supporting children in learning about composed units and scalar ratio relationships. However, research has shown that double number lines visualize less explicitly the functional rate relationship between two measure spaces (e.g., Orrill and Brown 2012; Beckmann and Izsák 2015). An important issue arises regarding how to design and complement lessons that highlight such a weakly visualized aspect.

\section{Conclusion}

In the present paper, we explored practice-based perspectives on teaching WNM that build a stepping stone toward proportional reasoning. Although our review is not exhaustive, we showed some teaching strategies that are integral to building early understanding of proportional relationships and proportional reasoning. Those strategies can be said to nurture children's ratio reasoning and use of composed units by progressively giving children the experience of building up and down and allowing them to reflect on it. Herein, the focus was on scalar ratio relationships. Regarding functional rates (or the multiplicative relationship between measure spaces), the reviewed studies suggest two strategies. One is to build a basis for relative thinking by linking WNM to measurement and the meaning of bai. The other is to develop children's reified conception of ratio as a composed unit by providing them with meaningful contexts of using ratio as a composed unit to solve problems. In both strategies, the linear representation provides a means of scaffolding the learning of reasoning proportionally. Nevertheless, further challenges remain as addressed herein. We continue to ask how we can prepare children to move toward a powerful and flexible mental image of multiplication and proportional reasoning in the teaching of WNM.

Open Access This article is distributed under the terms of the Creative Commons Attribution 4.0 International License (http://creativeco mmons.org/licenses/by/4.0/), which permits unrestricted use, distribution, and reproduction in any medium, provided you give appropriate credit to the original author(s) and the source, provide a link to the Creative Commons license, and indicate if changes were made.

\section{References}

Aoyama, S. (2013). Wariai no mikata kangaekata wo sodateru shidou no kuhuu: Suutyokusenzu jou de taiou suru suuryou wo sousa suru katsudou wo tooshite [Lessons designed for developing the concepts and ideas of ratio and rate: Through manipulation of corresponding numbers and quantities on the number line diagrams]. Journal of Japan Society of Mathematical Education, 95(10), 2-10.

Bass, H. (2015). Quantities, numbers, number names, and the real number line. In X. Sun, B. Kaur, \& J. Novotná (Eds.), Conference proceedings of ICMI Study 23: Primary mathematics study on whole numbers (pp. 10-19), June 3-7, University of Macau, Macao, China.

Beckmann, S., \& Izsák, A. (2015). Two perspectives on proportional relationships: Extending complementary origins of multiplication in terms of quantities. Journal for Research in Mathematics Education, 46(1), 17-38.

Christou, C., \& Philippou, G. (2002). Mapping and development of intuitive proportional thinking. Journal of Mathematical Behavior, 20, 321-336.

Clark, F., \& Kamii, C. (1996). Identification of multiplicative thinking in children in grades 1-5. Journal for Research in Mathematics Education, 27(1), 41-51.

Dole, S., Hilton, A., Hilton, G., \& Goos, M. (2015). Proportional reasoning: An elusive connector of school mathematics curriculum. In X. Sun, B. Kaur, \& J. Novotná (Eds.), Conference proceedings of ICMI Study 23: Primary mathematics study on whole numbers (pp. 534-541), June 3-7, University of Macau, Macao, China.

Fuson, C. (2003). Developing mathematical power in whole number operations. In J. Kilpatrick, W. G. Martin \& D. Schifter (Eds.), A research companion to principles and standards for school mathematics (pp. 68-94). Reston: The National Council of Teachers of Mathematics.

Harel, G., \& Confrey, J. (Eds.). (1994). The development of multiplicative reasoning in the learning of mathematics. Albany: State University of New York Press.

Hino, K. (2015). Research on proportional reasoning in the Japanese context. In B. Sriraman, J. Cai, K.-H. Lee, L. Fan, Y. Shimizu, C. S. Lim \& K. Subramaniam (Eds.), The first sourcebook on Asian research in mathematics education: China, Korea, Singapore, Japan, Malaysia, and India (pp. 1323-1352). Charlotte: Information Age Publishing.

Ichikawa, K. (2010). Bai gainen no shinten wo unagasu shidou ni kansuru kousatsu: Dai 2 gakunen bai no dounyuu ni tyakumoku shite [A study of teaching that promotes students' understanding of bai: Focusing on the introduction of bai in the second grade]. Proceedings of the Annual Meeting of the Japan Society of Mathematical Education, 133-138. 
Iwasawa, A., \& Hino, K. (2011). Sansuuka niokeru sojitekina gakusyuukatudou nituitenokenkyuu: Suutyokusen ni syouten wo atete [A study of mathematical activity that lays the foundation for the learning of related mathematical content: Focusing on the number line]. University Bulletin of Utsunomiya University, 34, 49-56.

Kako, K. (2015). Kijyunryo wo ishiki saseru dai 1 gakunen okisakurabe no shido [Teaching of "comparing the size of quantity" that makes conscious the base quantity in the first grade]. Journal of Japan Society of Mathematical Education, 97, 2-10.

Kaput, J. J., \& West, M. M. (1994). Missing-value proportional reasoning problems: Factors affecting informal reasoning patterns. In G. Harel \& J. Confrey (Eds.), The development of multiplicative reasoning in the learning of mathematics (pp. 237-287). Albany: State University of New York Press.

Kaur, B. (2015). The model method: A tool for representing and visualizing relationships. In X. Sun, B. Kaur, \& J. Novotná (Eds.), Conference proceedings of ICMI Study 23: Primary mathematics study on whole numbers (pp. 448-455), June 3-7, University of Macau, Macao, China.

Kugaya, A. (2017). Bai no kangae wo hagukumu gakusyuu: Dai 4 gakunen "syousuu bai" no gakusyuu ni syouten wo atete [Nurturing ideas of "how many times": Focusing on decimal numbers in grade 4]. Journal of Japan Society of Mathematical Education, 99(8), 4-13.

Lamon, S. J. (1994). Ratio and proportion: Cognitive foundations in unitizing and norming. In G. Harel \& J. Confrey (Eds.), The development of multiplicative reasoning in the learning of mathematics (pp. 89-120). Albany: State University of New York Press.

Lamon, S. J. (2005). Teaching fractions and ratios for understanding (2nd ed). Mahwah: Lawrence Erlbaum Associates.

Lamon, S. J. (2007). Rational numbers and proportional reasoning: Toward a theoretical framework for research. In F. Lester (Ed.), Second handbook of research on mathematics teaching and learning (pp. 629-668). Charlotte: Information Age Publishing.

Lesh, R., Post, T., \& Behr, M. (1988). Proportional reasoning. In J. Herbert \& M. Behr (Eds.), Number concepts and operations in the middle grades (pp. 93-118). Reston: NCTM.

Lo, J. J., \& Watanabe, T. (1997). Developing ratio and proportion schemes: A story of a fifth grader. Journal for Research in Mathematics Education, 28(2), 216-236.

Lobato, J., Ellis, A. B., Charles, R. I., \& Zbiek, R. M. (2010). Developing essential understanding of ratios, proportions, and proportional reasoning for teaching mathematics in grades 6-8. Reston: The National Council of Teachers of Mathematics.

Ministry of Education, Culture, Sports Science and Technology. (2008). Elementary school teaching guide for the Japanese course of study: Mathematics. (English translation was carried out by the Asia-Pacific Mathematics and Science Education Collaborative at DePaul University in Chicago, Illinois, U.S.A., under contract from the U.S. Department of Education).

Modestou, M., \& Gagatsis, A. (2010). Cognitive and metacognitive aspects of proportional reasoning. Journal of Mathematical Thinking and Learning, 12(1), 36-53.

Mulligan, J. (2011). Towards understanding the origins of children's difficulties in mathematics learning. Australian Journal of Learning Difficulties, 16(1), 19-39.

Nakamura, K. (2011). Seisuu no jouhou/johou no mondaibamen deno 4 nensei no kodomo no hireitekisuiron no jittai [Students' proportional reasoning on multiplication and division problem situations]. Journal of Japan Society of Mathematical Education, 93(6), 2-10.

Ng, S. F., \& Lee, K. (2009). The model method: Singapore children's tool for representing and solving algebraic word problems. Journal for Research in Mathematics Education, 40(3), 282-313.
Nunes, T., Dorneles, B. V., Lin, P. J., \& Rathgeb-Schnierer, E. (2016). Teaching and learning about whole numbers in primary school. In ICME-13 Topical surveys, teaching and learning about whole numbers in primary school. Cham: Springer. https://doi. org/10.1007/978-3-319-45113-8_1.

Nunokawa, K. (2007). Syougakkou 3-nensei niyoru hireitekisuiron no kadai no kaiketsu: Kaitani no riyou ni syouten wo atete [A case study of the third-grade students' problem solving processes of proportional reasoning: Focusing on the use of unit]. Joetsu Journal of Mathematics Education, 22, 1-12.

Orrill, C. H., \& Brown, R. E. (2012). Making sense of double number lines in professional development: Exploring teachers' understandings of proportional relationships. Journal of Mathematics Teacher Education, 15, 381-403.

Resnick, L. B., \& Singer, J. A. (1993). Protoquantitative origins of ratio reasoning. In T. P. Carpenter, E. Fennema \& T. A. Romberg (Eds.), Rational numbers: An integration of research (pp. 107130). Hillsdale: Lawrence Erlbaum Associates.

Sato, E. (2009). 3 nen: suuchokusen no yosa ga wakaru shidou: "Kakezan" "warizan" no shidou wo tooshitet [Lessons in which we can make good use of the idea of proportion]. Elementary Mathematics Teaching Today, 463, 12-15 (Tokyo: Toyokan).

Shield, M., \& Dole, S. (2013). Assessing the potential of mathematics textbooks to promote deep learning. Educational Studies in Mathematics, 82, 183-199.

Society of Elementary Mathematics Education (2011). Seisuu no keisan [Whole number arithmetic]. Tokyo: Toyokan.

Stigler, J. W., \& Hiebert, J. (1999). The teaching gap. New York: Free Press.

Sugiyama, Y. (2008). Syotouka suugakuka kyouikugaku josetsu [Introduction to elementary mathematics education]. Tokyo: Toyokan.

Tabata, T. (2001). Syousuu bai no dounyuu nituiteno itikousatsu: Syousuubai ni arawasu yosa ni syouten wo atete [A study on introduction to bai with decimal numbers: Focusing on appreciation of representing bai with decimal numbers]. Journal of Japan Society of Mathematical Education, 83(12), 2-12.

Tabata, T. (2008). Seisuu no jouhou niokeru hireikankei no kenzaika ni kansuru jugyou no kousatu: 1atari ryou wo shimesanai mondai wo suutyokusen wo kaku shidou wo tooshite [A lesson study on making proportional relationships explicit in the whole number multiplication: Through the teaching of writing a number-line diagram to solve the mathematical task that do not show the information on the unit value]. Proceedings of the Annual Meeting of the Japan Society of Mathematical Education, 339-344.

Takahashi, T. (2015). Syougakkou 3 nensei niokeru 1 tomiru mikata no shidou ni kansuru itikousatsu: 1 atari to miru ookisa wo kangaeru mondai wo daizaini [An idea for teaching students to identify the base quantities in the third grade: Using mathematics tasks that require students to think about the size of unit quantities]. Journal of Japan Society of Mathematical Education, 97(6), 2-12.

Takashima, J. (1999). Seisuu no jouhou no imirikai ni kansuru kenkyuu: S-o-kun, O-o-kun no jirei wo tooshite [A study on understanding whole number multiplication: A case study of two children S-o-kun and O-o-kun]. Proceedings of the Annual Meeting of the Japan Society of Mathematical Education, 287-292.

Tanaka, H. (2016). Imi no kakuchou wo unagasu suutyokusen no arikata: Dai 6 gakunen "bunsuu no kakezan" [Exploration of number line representation for the extension of meaning of multiplication: Multiplication of fraction in the sixth grade]. Elementary Mathematics Teaching Today, 550, 20-23 (Tokyo: Toyokan).

Van Dooren, W., De Bock, D., \& Verschaffel, L. (2010). From addition to multiplication ... and back: The development of students' additive and multiplicative reasoning skills. Cognition and Instruction, 28(3), 360-381. 
Vergnaud, G. (1983). Multiplicative structures. In R. Lesh \& M. Landau (Eds.), Acquisition of mathematics concepts and processes (pp. 127-174). New York: Academic Press.

Vergnaud, G. (1994). Multiplicative conceptual field: What and why? In G. Harel \& F. Confrey (Eds.), The development of multiplicative reasoning in the learning of mathematics (pp. 41-59). Albany: State University of New York Press.

Verschaffel, L., Greer, G., \& De Corte, E. (2007). Whole number concepts and operations. In F. Lester (Ed.), Second handbook of research on mathematics teaching and learning (pp. 557-628). Charlotte: Information Age Publishing.
Watanabe, T. (2011). Shiki: A critical foundation for school algebra in Japanese elementary school mathematics. In J. Cai \& E. Knuth (Eds.), Early algebraization: Advances in mathematics education (pp. 109-124). New York: Springer.

Young-Loveridge, J., \& Bicknell, B. (2015). Using multiplication and division context to build place-value understanding. In X. Sun, B. Kaur, \& J. Novotná (Eds.), Conference proceedings of ICMI Study 23: Primary mathematics study on whole numbers (pp. 379-386), June 3-7, University of Macau, Macao, China. 